\title{
LIGANTES ASFÁLTICOS MODIFICADOS COM RESÍDUOS: UMA REVISÃO DE LITERATURA
}

\author{
M. E. Guimarães ${ }^{1}$; R. O. Souza ${ }^{2}$ \\ 1,2 Universidade Federal da Integração Latino-Americana (UNILA), Av. Tancredo Neves, no 6713, \\ Parque Tecnológico da Itaipu (PTI), Foz do Iguaçu/PR \\ marciogeng@hotmail.com ${ }^{1}$,ricardo.souza@unila.edu.br $r^{2}$
}

Resumo: No Brasil, a pavimentação de ruas, avenidas e estradas é executada quase que totalmente com misturas asfálticas. Nessas misturas, o ligante asfáltico tem papel fundamental na coesão, resistência ao afundamento de trilha de roda, à fadiga e ao trincamento térmico. O desempenho desse ligante pode ser melhorado com a adição de modificadores (SBS, EVA, HDPE, borracha de pneus, etc.). Este artigo apresenta uma revisão de literatura sobre ligantes asfálticos modificados com resíduos, com o objetivo de apresentar o que tem se discutido e qual o real desempenho acerca desses materiais. Os trabalhos analisados foram pesquisados na base de dados Web of Science através de filtros com palavras chaves obtendo-se os artigos mais relevantes, cujos resultados são apresentados. Com o trabalho percebeu-se a crescente utilizaçáo de modificadores poliméricos, demonstrando que as propriedades desses materiais são propícias na produçáo de ligantes asfálticos modificados.

Palavras-chave: Ligante asfáltico, Resíduos, Desempenho.

\begin{abstract}
In Brazil, the paving of streets, avenues and roads is almost entirely executed with asphalt mixtures. In these mixtures, asphalt binder plays a fundamental role in cohesion, resistance to permanent deformation, fatigue and thermal cracking. Binder performance can be improved by the addition of modifiers such as SBS, EVA, HDPE, tire rubber, etc. This paper presents a literature review about residue modified asphalt binders, aiming to show what has been discussed and how is the real performance of these materials. The analysed papers were searched in the "Web of Science" database with key words filters to obtain the most relevant papers, whose results are presented. We identified an increasing use of polymeric modifiers, which shows that the properties of these materials are propitious for modified asphalt binders production.
\end{abstract}

Keywords: Asphalt binder, Wastes, Performance. 


\section{Introduçáo}

As estradas brasileiras, nos dias atuais, se encontram em um estado muito precário devido ao alto custo de manutenção, causando assim insegurança e prejuízo econômico. Nessa perspectiva, o estado de conservaçáo das rodovias impacta diretamente no desempenho econômico de uma determinada regiáo, ou mesmo de um País [1].

A superfície de rolamento de alguns pavimentos asfálticos, com o passar do tempo, começa a apresentar defeitos, esses causam desconforto, reduzem a segurança e consequentemente elevam os custos para os usuários. Trincas por fadiga e o acúmulo de deformação permanente nas trilhas de rodas são os principais defeitos dos pavimentos asfálticos. Uma das causas dessas ocorrências é a baixa resistência ao cisalhamento das misturas asfálticas, que depende da susceptibilidade térmica do ligante asfáltico [2]. Pesquisas tem se intensificado cada vez mais nessa área, analisando as ocorrências de defeitos e como solucioná-los. Um exemplo de solução que pode ser adotada para corrigir esses problemas é a utilização de modificadores para ligantes asfálticos, com o intuito de melhorar a qualidade do ligante e, consequentemente, melhorar o desempenho do pavimento. Nesse contexto, modificadores como SBS, EVA, polímeros, borracha de pneus, etc., na pavimentação asfáltica, melhoram o desempenho dos asfaltos, contribuindo para a redução da formação de defeitos efetivos [3, 4].

Estudos sobre incorporação de resíduos em ligantes asfálticos têm aumentado nos últimos anos incisivamente. Os resíduos são oriundos das atividades humanas e da natureza, podendo assim, além de tudo, contribuir com a proteção ao meio ambiente.

O betume ou ligante asfáltico é caracterizado como um material viscoelástico que apresenta boas propriedades mecânicas e reológicas. Como o crescimento do número de veículos nas estradas é continuo, é necessário que haja um melhoramento nas propriedades (resistência, fadiga, fissuras a baixa temperatura, etc..) dos asfaltos [4].

Este trabalho de revisão apresenta uma pesquisa bibliográfica sobre ligantes asfálticos modificados com resíduos. Ao longo do artigo é explanado sobre o desempenho dos ligantes asfálticos encontrados na base de dados Web of Science para a pesquisa. É apresentada uma tabela resumo onde é possível notar quais foram os principais resultados obtidos pelos autores nas pesquisas, como também o resíduo modificador e as características de preparo da mistura asfáltica.

\section{Metodologia}

A revisão de literatura é utilizada para tratar sobre o tema e o problema abordado. Através do processo de levantamento e análise da literatura publicada é traçado um quadro teórico em que se sustentará o desenvolvimento da pesquisa [5]. 
Para a elaboração da presente revisão de literatura cinco etapas foram seguidas: Etapa 1: Lacuna a ser preenchida com a revisão - Os ligantes asfálticos modificados com resíduo vêm sendo estudados com maior ênfase nos últimos anos? Pode-se saber o que tem se discutido a respeito desses materiais e qual o desempenho dos mesmos?

Etapa 2: Escolha da base de dados - A base escolhida para esta revisão foi a Web of Science. A escolha se deu por ser uma das bases de dados mais usadas pelo meio acadêmico mundial, e também por ser uma base multidisciplinar que indexa somente os periódicos mais citados em suas respectivas áreas. $\mathrm{O}$ acesso se deu através do site da Comissão de Aperfeiçoamento de Pessoal de Nível Superior (Capes), com liberação para estudantes da Universidade Federal da Integração Latino-Americana (UNILA).

Etapa 3: Definição de terminologia base (palavras chaves da pesquisa) - Foram definidas as terminologias adotadas para a pesquisa, onde adotou-se as palavras chaves: asphalt* binder, modifier, bitumen e waste (as palavras foram pesquisadas em inglês para que a busca se ampliasse, não ficando os resultados restritos à publicações em português).

Etapa 4: Critérios de inclusão e exclusão (definição do numero da amostra) - Na interface da base Web of Science, no item busca, foram inseridas as palavras "asphalt* binder modifier" retornando 414 arquivos, com o auxilio do termo "AND" (ferramenta de busca que significa "e") se acrescentou a palavra "bitumen", assim reduzindo para 207 arquivos. Por ser um número ainda expressivo adicionou-se mais uma palavra para restringir a busca em menos resultados e que os mesmos fossem mais específicos a temática abordada no artigo, nesse caso "and waste", resultando agora em 45 arquivos. O próximo passo foi fazer um filtro analisando títulos e resumos de cada publicação, observando a relevância do estudo e se o mesmo estaria no âmbito da investigaçáo, sendo descartados 35 artigos, dentre os quais esses eram artigos de revisão, análise dos agregados para pavimentação, analise reológica dos pavimentos. Alguns apresentavam apenas informaçóes sobre a funcionalidade do pavimento asfáltico, outros estudavam apenas o envelhecimento dos pavimentos e uns estavam fora do âmbito do estudo de ligante asfáltico. Assim, obteve-se uma amostra de estudo com 10 artigos. Foi incluído ao número final da amostra, mais um artigo, que apresenta o uso de resíduo de óxido de alumínio, por ser um estudo recente, ficando a amostra final do estudo de revisão constituída por 11 artigos.

Etapa 5: Análise, apresentação e discussão dos resultados obtidos - Criou-se uma tabela com todas as informaçôes necessárias para responder à pergunta que se teve em relação aos ligantes e possibilitar uma análise mais apurada dos dados obtidos e se chegar ao resultado que o trabalho buscava. Nessa tabela, incluiu-se para cada artigo, o título e ano da publicação, o(s) autor(es), resíduo modificador, tempo de mistura (minutos), temperatura de mistura $\left({ }^{\circ} \mathrm{C}\right)$, adição do modificador em peso (\%), o ligante base, velocidade de rotação durante o processo de mistura (rpm) e o resultado que o estudo apresentou. A apresentação desses resultados para a discussão foi realizada através de uma tabela resumo de forma descritiva, para possibilitar uma melhor compreensão e atingir de forma positiva e coerente o objetivo desse trabalho. 
Na Tabela 1, tem-se 11 trabalhos distintos, que abordam diferentes tipos de modificadores. Por mais que apresentem a utilização do mesmo resíduo modificador, mudando-se a concentração, logo as propriedades do ligante serão alteradas [6].

Ao se analisar o quadro resumo, percebeu-se que todos os trabalhos pesquisados na plataforma Web of Science tratam de ligantes asfálticos modificados com resíduos poliméricos das mais variadas formas. $\mathrm{O}$ único que não apresentou essa característica foi o trabalho incluído, proveniente de materiais metálicos, isso demostra que com o passar do tempo, as propriedades dos materiais poliméricos são propícias para utilização em ligantes asfálticos.

Os ligantes asfálticos modificados conferem às misturas betuminosas, menor susceptibilidade térmica e uma maior flexibilidade, ou seja, respondem com maior ênfase às solicitaçóes dos pavimentos, e também maior resistência ao envelhecimento durante a vida útil $[6,9]$.

Para a maioria das aplicaçóes rodoviárias, os asfaltos convencionais têm bom comportamento, satisfazendo plenamente os requisitos necessários para o desempenho adequado das misturas asfálticas sob o tráfego e sob as condiçôes climáticas. No entanto, para condiçôes de volume de veículos comerciais e peso por eixo crescente, ano a ano, em rodovias especiais ou nos aeroportos, em corredores de tráfego pesado canalizado e para condiçôes adversas de clima, com grandes diferenças térmicas entre inverno e verão, tem sido cada vez mais necessário o uso de modificadores das propriedades dos ligantes asfálticos [6].

\section{Resultados}

Na tabela resumo a seguir (Tabela 1) são apresentados em ordem cronológica os resultados obtidos pela pesquisa. 
Tabela 1 - Tabela resumo dos resultados da pesquisa.

\begin{tabular}{|c|c|c|c|c|c|c|c|c|}
\hline Titulo e Ano & Autores & $\begin{array}{c}\text { Resíduo } \\
\text { Modificador }\end{array}$ & $\begin{array}{l}\text { Tempo de } \\
\text { Mistura } \\
\text { (minutos) }\end{array}$ & $\begin{array}{c}\text { Temperatura } \\
\left({ }^{\circ} \mathrm{C}\right)\end{array}$ & $\begin{array}{l}\text { Adição do } \\
\text { modificador } \\
\text { em peso }(\%)\end{array}$ & $\begin{array}{l}\text { Ligante } \\
\text { Base }\end{array}$ & $\begin{array}{l}\text { Velocidade de } \\
\text { rotaçáo durante } \\
\text { a mistura (rpm) }\end{array}$ & Resultados \\
\hline $\begin{array}{l}\text { Utilização de resíduos } \\
\text { de polietileno de alta } \\
\text { densidade como modi- } \\
\text { ficador de betume em } \\
\text { mistura de concreto } \\
\text { asfáltico (2004) }\end{array}$ & $\begin{array}{l}\text { Hinıslıoglu. S.; } \\
\text { Agar. E. }\end{array}$ & $\begin{array}{l}\text { Polietileno de } \\
\text { alta densidade } \\
\text { (HDPE) }\end{array}$ & 5,15 e 30 & 145,155 e 165 & 4,6 e 8 & $60 / 70$ & 200 & $\begin{array}{l}\text { Melhorou a resistência á deformaçóes permanentes } \\
\text { devido à sua alta estabilidade, apresentou maior } \\
\text { rigidez, com maior capacidade de aplicaçấo de carga } \\
\text { no pavimento. }\end{array}$ \\
\hline $\begin{array}{l}\text { Comportamento } \\
\text { termo-reológico e } \\
\text { estabilidade de arma- } \\
\text { zenamento de betumes } \\
\text { modificados com pneu } \\
\text { moído de borracha } \\
(2004)\end{array}$ & $\begin{array}{l}\text { Navarro. F. J.; } \\
\text { Partal. P.; Mar- } \\
\text { tı冈nez-Boza. F.; } \\
\text { Gallegos. C. }\end{array}$ & Borracha de pneu & 90 & 180 & 9 & $60 / 70$ & 1200 & $\begin{array}{l}\text { Melhorou a resistência a deformaçóes permanente } \\
\text { em altas temperatura, como também à fissuraçáo } \\
\text { térmica e aumentou a flexibilidade do betume a } \\
\text { baixas temperaturas. }\end{array}$ \\
\hline $\begin{array}{l}\text { Uso de polietileno de } \\
\text { alta densidade reci- } \\
\text { clado irradiado como } \\
\text { modificador para } \\
\text { betume (2017) }\end{array}$ & $\begin{array}{l}\text { Ahmedzade. } \\
\text { P.; Günay. T.; } \\
\text { Grigoryeva. O.; } \\
\text { Starostenko. O. }\end{array}$ & $\begin{array}{l}\text { Polietileno de } \\
\text { alta densida- } \\
\text { de reciclado } \\
\text { (HDPER) }\end{array}$ & 15 & 170 & $1,3,5,7$ e 9 & $160 / 220$ & 1300 & $\begin{array}{l}\text { Melhorou a temperatura de suscetibilidade do } \\
\text { betume e as propriedades físicas, permitindo que o } \\
\text { modificador possa ser usado como betume especial } \\
\text { para evitar deformaçôes permanentes. }\end{array}$ \\
\hline $\begin{array}{l}\text { Propriedades reo- } \\
\text { lógicas do estireno } \\
\text { butadieno de borracha } \\
\text { em ligante betuminoso } \\
\text { modificado (2016) }\end{array}$ & $\begin{array}{l}\text { Yaacob. H.; } \\
\text { Mughal. M. } \\
\text { A.; Jaya. R. P.; } \\
\text { Hainina. M. R.; } \\
\text { Jayantib, D. S.; } \\
\text { Wanc. C. N. C. }\end{array}$ & $\begin{array}{l}\text { Estireno butadie- } \\
\text { no de borracha } \\
\quad \text { (SBR) }\end{array}$ & 60 & 130 a 140 & $1,2,3,4$ e 5 & $60 / 70$ & 800 a 1000 & $\begin{array}{l}\text { Aumentou significativamente a viscosidade do ligan- } \\
\text { te a altas temperaturas. A viscosidade significa que } \\
\text { haverá menos chance de perder a resistência a altas } \\
\text { temperaturas e resistirá à esforço maiores de carga. }\end{array}$ \\
\hline $\begin{array}{l}\text { Efeito da adiçáo de } \\
\text { resíduo de polímero } \\
\text { na reologia do betume } \\
\text { modificado (2006) }\end{array}$ & $\begin{array}{l}\text { García-Morales. } \\
\text { M.; Partal. P.; } \\
\text { Navarro. F. J.; } \\
\text { Gallegos. C. }\end{array}$ & $\begin{array}{c}\text { Acetato de Vinil } \\
\text { de etileno (EVA); } \\
\text { EVA+Polietileno } \\
\text { de baixa } \\
\text { densidade } \\
\text { (EVA/LDPE); } \\
\text { Acrilonitrilo } \\
\text { butadieno } \\
\text { estireno (ABS) e } \\
\text { Borracha de pneu }\end{array}$ & 360 & 180 & $\begin{array}{c}\text { EVA - } 5 \text { e } 9 ; \\
\text { EVA/LDPE - } 5 \\
\text { e 9; ABS - 9; } \\
\text { Borracha de pneu } \\
\text { - 9; (EVA/LDPE } \\
\text { + Borracha } \\
\text { de pneu) - } 5 \\
(2,5+2,5), 7 \\
(3,5+3,5) \text { e } 9 \\
(4,5+4,5)\end{array}$ & $60 / 70$ & 1200 & $\begin{array}{l}\text { A borracha de pneu tornou-se o aditivo mais inte- } \\
\text { ressante para a modificaçấo a baixas temperaturas } \\
\text { fornecendo maior flexibilidade, o que o torna mais } \\
\text { resistente em relaçáo aos carregamentos devido ao } \\
\text { alto trafego. A mistura composta por EVA e EVA/ } \\
\text { LDPE exibe resultados bastante promissores á altas } \\
\text { temperaturas. O ABS não mostra qualquer tipo de } \\
\text { afinidade pelos compostos de ligantes betuminosos. } \\
\text { Nas misturas que foram adicionados dois tipo de } \\
\text { resíduos (EVA/LDPE) + Borracha de pneu com } 7 \% \\
(3,5+3,5) \text { melhorou o seu comportamento térmico } \\
\text { em relaçấo à temperatura como um todo. }\end{array}$ \\
\hline
\end{tabular}




\begin{tabular}{|c|c|c|c|c|c|c|c|c|}
\hline Titulo e Ano & Autores & $\begin{array}{c}\text { Resíduo } \\
\text { Modificador }\end{array}$ & $\begin{array}{l}\text { Tempo de } \\
\text { Mistura } \\
\text { (minutos) }\end{array}$ & $\begin{array}{c}\text { Temperatura } \\
\left({ }^{\circ} \mathrm{C}\right)\end{array}$ & $\begin{array}{l}\text { Adiçáo do } \\
\text { modificador } \\
\text { em peso }(\%) \\
\end{array}$ & $\begin{array}{l}\text { Ligante } \\
\text { Base }\end{array}$ & $\begin{array}{l}\text { Velocidade de } \\
\text { rotaçáo durante } \\
\text { a mistura (rpm) }\end{array}$ & Resultados \\
\hline $\begin{array}{l}\text { Modificaçáa do be- } \\
\text { tume com Polímeros } \\
\text { reativo e não-reativo } \\
\text { (virgem e reciclado): } \\
\text { Uma análise compara- } \\
\text { tiva (2009) }\end{array}$ & $\begin{array}{l}\text { Navarroa. F. } \\
\text { J.; Partala. P.; } \\
\text { García-Moralesa. } \\
\text { M.; Martín- } \\
\text { Alfonsoa. M. J.; } \\
\text { Martínez-Bozaa. } \\
\text { F.; Gallegosa. } \\
\text { C.; Bordadob. J. } \\
\text { C. M.; Diogoc. } \\
\text { A .C. }\end{array}$ & $\begin{array}{l}\text { Não-reativos: } \\
\text { EVA; EVA/ } \\
\text { LDPE; Estireno } \\
\text { butadieno } \\
\text { estireno (SBS); } \\
\text { Borracha de } \\
\text { pneu e Reativos: } \\
\text { Difenilmetano } \\
\text { diisocianato - } \\
\text { Polietileno glicol } \\
\text { (MDI-PEG). }\end{array}$ & 50,90 e 120 & 180 e 90 & $\begin{array}{l}\text { EVA - 5; EVA/ } \\
\text { LDPE - 5; SBS } \\
\text { - 3; Borracha de } \\
\text { pneu - 9; MDI- } \\
\text { PEG - } 0,5,1 \\
\text { e } 1,5\end{array}$ & $60 / 70$ & 1200 & $\begin{array}{l}\text { O uso de EVA/LDPE com } 5 \% \text { de adição em peso, } \\
\text { proporcionou maior viscoelasticidade em todas as } \\
\text { faixas de temperatura. O EVA e o SBS apresentaram } \\
\text { aumento de viscoelasticidade em baixas temperatu- } \\
\text { ras. Os polímeros náo reativos são em grande parte } \\
\text { instáveis a alta temperatura. O MDI-PEG apresenta } \\
\text { significativo aumento em relaçáo a oxidaçáo. Em- } \\
\text { bora esse polímero reativo não induzir modificaçấo } \\
\text { significativa no ligante resultante, logo após o pro- } \\
\text { cessamento, o módulos viscoelásticos e viscosidade } \\
\text { aumentaram significativamente quando curado em } \\
\text { temperatura ambiente. }\end{array}$ \\
\hline $\begin{array}{l}\text { Modificadores de } \\
\text { betume de asfalto } \\
\text { para temperatura } \\
\text { reduzida: Uma Análi- } \\
\text { se comparativa } \\
\text { entre três aditivos } \\
\text { poliméricos e não } \\
\text { poliméricos (2014) }\end{array}$ & $\begin{array}{l}\text { Cuadri. A. A.; } \\
\text { Carrera. V.; } \\
\text { Izquierdo. M. } \\
\text { A.; García- } \\
\text { Morales. M.; } \\
\text { Navarro. F.J. }\end{array}$ & $\begin{array}{c}\text { Não Poliméricos: } \\
\text { Dióxido de } \\
\text { tioureia (ThD); } \\
\text { Tioureia (Th) } \\
\text { Polimérico: } \\
\text { Difenilmetano } \\
\text { disocianato - } \\
\text { polipropileno } \\
\text { glicol (MDI- } \\
\text { PPG) }\end{array}$ & 60 & 130,180 e 90 & $\begin{array}{l}\text { ThD - } 3 \text { e } 9 ; \text { Th } \\
\text { - } 3 \text { e } 9 \text { e MDI- } \\
\text { PPG - } 4\end{array}$ & $150 / 200$ & 1200 & $\begin{array}{l}\text { As análises revelaram que os ligantes modificados } \\
\text { betuminosos evoluíram para materiais altamente } \\
\text { viscosos quando submetidos à cura ambiente, } \\
\text { podem contribuir na reduçáa da temperatura do } \\
\text { asfalto durante o processo de mistura. Espera-se } \\
\text { que eles sofram um aumento na viscosidade quan- } \\
\text { do estiverem em serviço, logo melhoraria ainda } \\
\text { mais seu desempenho como um todo. }\end{array}$ \\
\hline $\begin{array}{l}\text { Uso de Geomembra- } \\
\text { nas Recuperadas para } \\
\text { modificação de de- } \\
\text { sempenho mecânico } \\
\text { de ligantes betumi- } \\
\text { nosos (2016) }\end{array}$ & $\begin{array}{l}\text { García-Travé. } \\
\text { G.; Tauste. R.; } \\
\text { Navarro F. N.; } \\
\text { Sánchez. M. } \\
\text { S.; Gámez. M. } \\
\text { C. R. }\end{array}$ & $\begin{array}{c}\text { Geomembranas } \\
\text { Recuperadas } \\
\text { (RG) }\end{array}$ & 60,90 e 120 & 165 & 3,5 e 7 & $50 / 70$ & 350 & $\begin{array}{l}\text { Aumentou a resistência à deformaçáo permanente, } \\
\text { a rigidez e a elasticidade, reduzindo a variaçáo } \\
\text { de temperatura e assim estende sua vida útil em } \\
\text { relaçáo a fadiga, o que pode resultar em maior } \\
\text { desempenho contra deformação plástica, particu- } \\
\text { larmente em altas temperaturas. }\end{array}$ \\
\hline $\begin{array}{l}\text { Formulaçáo e pro- } \\
\text { cessamento de ma- } \\
\text { teriais reciclados de } \\
\text { polietileno de baixa } \\
\text { densidade } \\
\text { Emulsóes de betume } \\
\text { modificado para as- } \\
\text { falto de temperatura } \\
\text { reduzida Tecnologias } \\
\text { (2016) }\end{array}$ & $\begin{array}{l}\text { Cuadri.A. A.; } \\
\text { Roman. C.; } \\
\text { García-Morales. } \\
\text { M.; Guisado. } \\
\text { F.; Moreno. E.; } \\
\text { Partal. P. }\end{array}$ & $\begin{array}{l}\text { Polietileno de } \\
\text { baixa densidade } \\
\text { reciclado } \\
\text { (LDPER) }\end{array}$ & 60 & 170 & $2,3,4$ e 5 & $\begin{array}{c}160 / 220 \text { e } \\
70 / 100\end{array}$ & 5000 & $\begin{array}{l}\text { Melhorou a viscosidade e o desempenho do be- } \\
\text { tume em altas temperaturas, logo aumentando a } \\
\text { resistência permanente, assim resistindo às defor- } \\
\text { maçôes de afundamento de roda nos pavimentos. }\end{array}$ \\
\hline
\end{tabular}




\begin{tabular}{|c|c|c|c|c|c|c|c|c|}
\hline Titulo e Ano & Autores & $\begin{array}{c}\text { Resíduo } \\
\text { Modificador }\end{array}$ & $\begin{array}{l}\text { Tempo de } \\
\text { Mistura } \\
\text { (minutos) }\end{array}$ & $\begin{array}{c}\text { Temperatura } \\
\left({ }^{\circ} \mathrm{C}\right)\end{array}$ & $\begin{array}{l}\text { Adiçáo do } \\
\text { modificador } \\
\text { em peso }(\%)\end{array}$ & Ligante Base & $\begin{array}{l}\text { Velocidade de } \\
\text { rotaçáo durante } \\
\text { a mistura (rpm) }\end{array}$ & Resultados \\
\hline $\begin{array}{l}\text { Modificação das } \\
\text { características } \\
\text { térmicas e reológicas } \\
\text { do betume por } \\
\text { misturas de } \\
\text { Resíduos de PET / } \\
\text { GTR (2016) }\end{array}$ & $\begin{array}{l}\text { Karahrodi. M. } \\
\text { H.; Jazani. O. } \\
\text { M.; Paran. S. M. } \\
\text { R.; Formela. K.; } \\
\text { Saeb. M. R. }\end{array}$ & $\begin{array}{l}\text { Resíduo de } \\
\text { tereftalato de } \\
\text { polietileno } \\
\text { (wPET) / } \\
\text { Borracha de } \\
\text { peneu de terra } \\
\text { (GTR) }\end{array}$ & $15+45$ & 150 & 3,5 e 7 & $60 / 70$ & $\begin{array}{c}\text { Inicial } 350 \\
\text { Continuado com } \\
3000\end{array}$ & $\begin{array}{l}\text { Melhorou as suas propriedades de } \\
\text { processamento (viscosidade, estabi- } \\
\text { lidade térmica), rigidez e resistência } \\
\text { permanente á altas temperaturas. }\end{array}$ \\
\hline $\begin{array}{l}\text { Caracterizaçáo de } \\
\text { desempenho de } \\
\text { Nanoparticulas de } \\
\text { oxído de alumínio } \\
\text { em ligante asfáltico } \\
\text { modificado (2016) }\end{array}$ & $\begin{array}{l}\text { Albrka Alia. S. } \\
\text { I; Ismaila. A.; } \\
\text { Yusoffa. N. I. } \\
\text { M.; Hassanb. N. } \\
\text { A.; Ibrahima. A. } \\
\text { N. H. }\end{array}$ & $\begin{array}{l}\text { Nanoparticulas de } \\
\text { oxído de alumínio } \\
\qquad\left(\mathrm{AL}_{2} \mathrm{O}_{3}\right)\end{array}$ & 90 & 170 & 3,5 e 7 & $60 / 70$ & 5000 & $\begin{array}{l}\text { Descobriu-se que a dureza dos ligan- } \\
\text { tes de asfalto modificados aumentou } \\
\text { com a adição de nano AL2O3 até } \\
5 \% \text {. Com o resultado do aumento } \\
\text { da dureza, o ponto de amolecimento } \\
\text { do asfalto modificado melhora em } \\
\text { relaçáo ao ligante de base. As proprie- } \\
\text { dades reológicas dos ligantes modi- } \\
\text { ficados foi melhorou á baixa e altas } \\
\text { temperaturas. }\end{array}$ \\
\hline
\end{tabular}


As propriedades dos ligantes asfálticos têm sido constantemente melhoradas por aditivos poliméricos nos últimos tempos. Os polímeros normalmente usados na modificação de ligantes asfálticos incluem copolímero de estireno-butadieno-estireno (SBS), borracha de estireno-butadieno (SBR), etileno acetato de vinilo (EVA), polietileno (LDPE, HDPE, etc.) e polímeros de resíduos (plásticos da agricultura, borracha de pneu, etc.). As suas características de mistura em betume podem afetar significativamente as propriedades das misturas resultantes, bem como os seus custos [6,7]. Em principio, esse melhoramento nas propriedades físicas e reológicas pode ser uma consequência de possíveis ligaçóes ou interaçóes químicas entre as moléculas do ligante com o polímero modificador, resultando na melhoria do desempenho dos ligantes tradicionais, através da resistência aos problemas de afundamento por trilha de roda, trincamento térmico e dano por fadiga [8]. Na Figura 1 são apresentadas as propriedades dos ligantes asfálticos melhoradas com a adição dos resíduos modificadores, de acordo com as pesquisas analisadas.

A deformação permanente, tanto a altas quanto a baixas temperaturas, e à rigidez, são as propriedades mais decorrentes das modificaçôes ocorridas pela adição do resíduo nos trabalhos analisados. Isso ocorre pela dificuldade que os ligantes asfálticos convencionais tem de resistir aos defeitos.

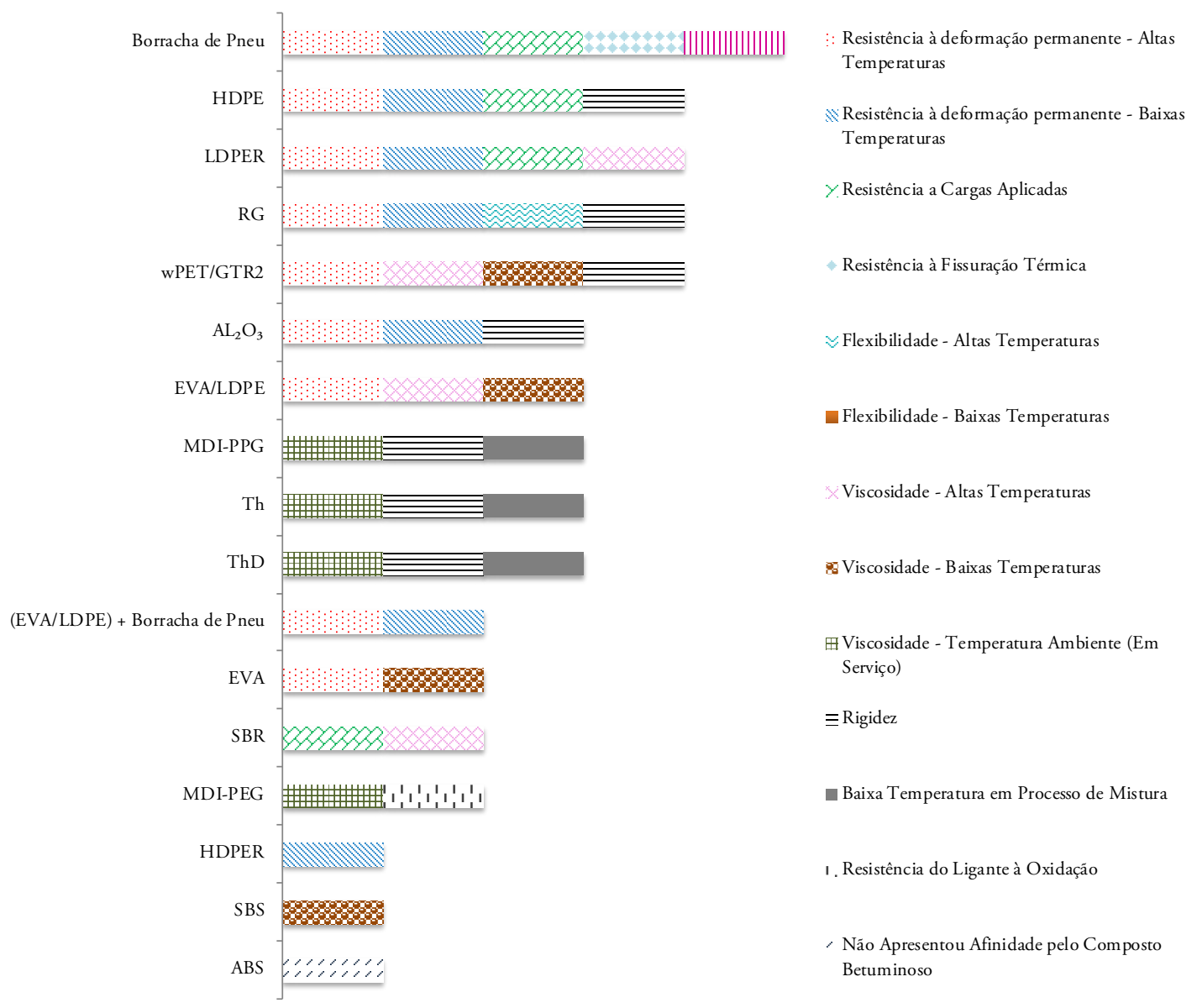

Figura 1 - Propriedades dos ligantes asfálticos melhoradas com a adição dos resíduos modificadores. 
O defeito à deformaçáo permanente é uma das preocupaçóes, quando se pensa em pavimentação asfáltica, podendo ser devido à manifestação de dois fenômenos, isoladamente ou combinados: a consolidação das camadas do pavimento ou algum problema associado ao projeto ou à execução da mistura asfáltica que leve à pós-compactação excessiva ou ao fluxo plástico sem variação volumétrica da mistura asfáltica. A deformação permanente nos revestimentos asfálticos é caracterizada por depressôes longitudinais nas trilhas de roda, as quais aumentam com as solicitaçóes das cargas repetidas impostas pelo tráfego de veículos [10].

Trata-se de um problema observado principalmente em lugares de clima tropical, onde as temperaturas dos pavimentos asfálticos são muito elevadas. Por se notar isso, vem a importância de pesquisas que busquem materiais ou combinaçôes dos mesmos que retardem e/ou amenizem esse defeito. Muitos estudos abordaram a modificação de ligantes asfálticos com utilização de diversos tipos de aditivos. Essas modificaçôes visam a melhoria de propriedades da mistura asfáltica, tais como: (i) resistência à deformação permanente, (ii) resistência à fadiga, (iii) resistência ao trincamento térmico, (iv) resistência ao dano por umidade (melhoria da aderência na interface agregado-ligante), maior rigidez do pavimento, entre outras [4].

A resistência à deformação permanente é afetada pela baixa influência do ligante asfáltico, isso devido ao fato que, com o aumento da temperatura, a consistência do ligante asfáltico diminui e, em temperaturas elevadas, independentemente da maior ou menor consistência, todo ligante asfáltico apresenta comportamento predominantemente viscoso, o que favorece a deformaçáo permanente da mistura asfáltica [11].

\section{Conclusóes}

Com base na análise da pesquisa observou-se uma crescente utilização de modificadores poliméricos, demonstrando que esses materiais são propícios para produção de ligantes asfálticos modificados, pois dos 11 artigos analisados, 10 usam polímeros como resíduo modificador, exceto pelo artigo que usou óxido de alumínio.

Identificou-se uma preocupação implícita em relação aos defeitos de deformação permanente e por fadiga, pois em 9 trabalhos é apresentado como resultado positivo do uso de resíduos em ligantes asfálticos a resistência à deformação permanente (temperaturas altas e baixas), como também à rigidez.

Ligantes asfálticos modificados têm se tornado um tema bastante comum em pesquisas científicas por sua relevante importância para setor rodoviário, devido ao seu alto custo de manutençấo. $\mathrm{O}$ que mais tem se discutido nos dias atuais em relação a esses materiais, diz respeito a encontrar modificadores que além de contribuir positivamente nas propriedades dos ligantes, ajudem a preservar o meio ambiente. 


\section{Agradecimentos}

Universidade Federal da Integração Latino-Americana (UNILA).

\section{Referências}

[1] MELO, J. V. S. Desenvolvimento e estudo do comportamento reológico e desempenho mecânico de concreto asfálticos modificados com nanocompósitos. 2014. Tese (Doutorado em Engenharia Civil) - Pós-graduaçáo em Engenharia Civil, Universidade Federal de Santa Catarina. Florianópolis, 2014. Disponível em: <https://repositorio. ufsc.br/handle/123456789/128794>. Acesso em: 18 jun. 2017.

[2] NEVES FILHO, C. L. D. Avaliaçáo laboratorial de misturas asfálticas SMA produzidas com ligante asfaltoborracha. 2004. Dissertação (Mestrado em Engenharia Civil) - Pós-graduação em Engenharia Civil, Escola de Engenharia de São Carlos da Universidade de São Paulo, São Carlos, 2004. Disponível em: <http://www.teses.usp.br/ teses/disponiveis/18/18137/tde-18122015-105039/en.php>. Acesso em: 18 jun. 2017.

[3] ROSA, A. P. G.; ROBERTO, A. S.; F, A. C.; ROGÉRIO D. D. R. Análise comparativa entre asfalto modificado com borracha reciclada de pneus e asfalto modificado com polímeros. Revista eletrônica Teoria e Prática na Engenharia Civil. Rio Grande do Sul, v, 12, n. 20, p.31-38, Nov.2012. Disponível em: <http://www.editoradunas. com.br/revistatpec/Art4_N20.pdf>. Acesso em: 18 jun. 2017.

[4] YILDIRIM, Y. Polymer modified asphalt binders. Revista Internacional Contruction and Building Materials. v, 21, n. 1, p.66-72, Jan. 2007. Disponível em: <https://doi.org/10.1016/j.conbuildmat.2005.07.007>. Acesso em: 18 jun. 2017.

[5] SILVA, E.L.; MENEZES, E. M. Metodologia da pesquisa e elaboraçáo de dissertaçáo. Santa Catarina, Florianópolis, $4^{\mathrm{a}}$ ed. revisada e atualizada. 2005. Disponível em: <https://projetos.inf.ufsc.br/arquivos/Metodologia_ de_pesquisa_e_elaboracao_de_teses_e_dissertacoes_4ed.pdf $>$. Acesso em: 18 jun. 2017.

[6] BERNUCCI, L. B.; MOTTA, L. M. G.; CERATTI, J. A. P.; SOARES, J. B. Pavimentaçáo Asfáltica: Formação básica para engenheiros, Rio de Janeiro: PETROBRAS: ABEDA, 2006.

[7] AIT-KADI. A.; BRAHIMI. H.; BOUSMINA. M. Polymer blends for enhanced asphalt binders. Revista Polymer Engineering \& Science. v. 36, n. 12, p 1724-1733, Jun. 1996. Disponível em: <http://onlinelibrary.wiley. com/doi/10.1002/pen.10568/full>. Acesso em: 18 jun. 2017.

[8] SILVA, L. S. Contribuiçáo ao estudo do envelhecimento de Ligantes asfálticos. Influência da adiçáo de Polímeros e comportamento frente a radiaçáo UV. 2005. Tese (Doutorado em Engenharia) - Pós-graduação em Engenharia de Minas, Metalúrgica e de Materiais, Universidade Federal do Rio Grande do Sul, Rio Grande do Sul, 2005. Disponível em: <https://www.lume.ufrgs.br/bitstream/handle/10183/7349/000498535.pdf>. Acesso em: 18 jun. 2017.

[9] BRANCO, F.; PEREIRA, P.; SANTOS. L. P. Pavimentos rodoviários. Coimbra, 5a rp. 2016.

[10] MAHMOUD, A. F. F.; BAHIA, H. Using the Gyratory Compactor to Measure Mechanical Stability of Asphalt Mixtures, Wisconsin Highway Research Program. 2004. Disponível em: <https://minds.wisconsin.edu/ handle/1793/6907>. Acesso em: 18 jun. 2017.

[11] ONOFRE, F. C.; CASTELO BRANCO, V. T. F.; SOARES, J. B.; FAXINA, A. L. Avaliaçáo do efeito de ligantes asfálticos modificados na resistência à deformaçáo permanente de misturas asfálticas densas. Revista eletrônica Trasnportes. v. 21, n. 3, p.14-21, Set. 2013. Disponível em: <DOI:10.4237/transportes.v21i3.685>. Acesso em: 18 jun. 2017.

[12] HINISLIOGLU. S.; AGAR. E. Use of waste high density polyethylene as bitumen modifier in asphalt concrete mix. Materials Letters, v. 58, n. 3-4, p.267-271, jan. 2004. Disponível em: <Elsevier BV. http://dx.doi. org/10.1016/s0167-577x(03)00458-0>. Acesso em: 18 jun. 2017.

[13] NAVARRO, F. J.; PARTAL, P.; MARTÍNEZ-BOZA, F.; GALLEGOS, C. Thermo-rheological behaviour and storage stability of ground tire rubber-modified bitumens. Fuel, [s.l.], v. 83, n. 14-15, p.2041-2049, out. 2004. Disponível em: <Elsevier BV. http://dx.doi.org/10.1016/j.fuel.2004.04.003>. Acesso em: 18 jun. 2017. 
[14] GARCÍA-MORALES, M.; PARTAL, P.; NAVARRO. F. J.; GALLEGOS, C. Effect of waste polymer addition on the rheology of modified bitumen. Fuel, [s.1.], v. 85, n. 7-8, p.936-943, maio 2006. Disponível em: <Elsevier BV. http://dx.doi.org/10.1016/j.fuel.2005.09.015>. Acesso em: 18 jun. 2017.

[15] NAVARRO, F.J.; PARTALA, P.; GARCÍA-MORALESA, M.; MARTÍN-ALFONSOA, M. J.; MARTÍNEZBOZAA, F.; GALLEGOSA, C.; BORDADOB, J. C. M.; DIOGOC, A .C. Bitumen modification with reactive and non-reactive (virgin and recycled) polymers: A comparative analysis. Journal Of Industrial And Engineering Chemistry, [s.l.], v. 15, n. 4, p.458-464, jul. 2009. Disponível em: <Elsevier BV. http://dx.doi.org/10.1016/j. jiec.2009.01.003>. Acesso em: 18 jun. 2017.

[16] CUADRI, A. A.; CARRERA, V.; IZQUIERDO, M. A.; GARCÍA-MORALES, M.; NAVARRO, F.J. Bitumen modifiers for reduced temperature asphalts: A comparative analysis between three polymeric and non-polymeric additives. Construction And Building Materials, [s.l.], v. 51, p.82-88, jan. 2014. Disponível em: <Elsevier BV. http:// dx.doi.org/10.1016/j.conbuildmat.2013.11.009>. Acesso em: 18 jun. 2017.

[17] YAACOB, H.; MUGHAL, M.A.; JAYA, R.; HAININA, M. R.; JAYANTIB, D. S.; WANC, C. N. C. Rheological properties of styrene butadiene rubber modified bitumen binder. Jurnal Teknologi, [s.1.], v. 78, n. 7-2, p.121-126, 26 jul. 2016. Penerbit UTM Press. Disponível em: <http://dx.doi.org/10.11113/jt.v78.9503>. Acesso em: 18 jun. 2017.

[18] GARCÍA-TRAVÉ, G.; TAUSTE, R.; NAVARRO, F. N.; SÁNCHEZ, M. S.; GÁMEZ, M. C. R. Use of Reclaimed Geomembranes for Modification of Mechanical Performance of Bituminous Binders. Journal Of Materials In Civil Engineering, [s.l.], v. 28, n. 7, p.04016021/1 - 0401602/7, jul. 2016. American Society of Civil Engineers (ASCE). Disponível em: <http://dx.doi.org/10.1061/(asce)mt.1943-5533.0001507>. Acesso em: 18 jun. 2017.

[19] CUADRI, A. A.; ROMAN, C; GARCIA-MORALES, M.; GUISADO, F; MORENO, E.; PARTAL, P. Formulation and processing of recycled-low-density-polyethylene-modified bitumen emulsions for reducedtemperature asphalt technologies. Chemical Engineering Science, [s.1.], v.156, p.197-205, dez. 2016. Disponível em: <http://dx.doi.org/10.1016/j.ces.2016.09.018>. Acesso em: 18 jun. 2017.

[20] KARAHRODI, M. H.; JAZANI, O. M.; PARAN, S. M. R.; FORMELA, K. SAEB, M.R. Modification of thermal and rheological characteristics of bitumen by waste PET/GTR blends. Construction And Building Materials, v. 134, p.157-166, mar. 2017. Disponível em: <Elsevier BV. http://dx.doi.org/10.1016/j. conbuildmat.2016.12.134>. Acesso em: 18 jun. 2017.

[21] ALBRKA ALIA, S. I.; ISMAILA, A.; YUSOFFA, N. I. M.; IBRAHIMA, A. N. H. Characterization of the performance of aluminum oxide nanoparticles modified asphalt binder. Jurnal Teknologi, [s.1.], v. 78, n. 4, p.9196, 28 mar. 2016. Penerbit UTM Press. Disponível em: <http://dx.doi.org/10.11113/jt.v78.8003>. Acesso em: 18 jun. 2017.

[22] AHMEDZADE, P.; GÜNAY, T.; GRIGORYEVA, O.; STAROSTENKO, O. Irradiated Recycled High Density Polyethylene Usage as a Modifier for Bitumen. Journal Of Materials In Civil Engineering, [s.l.], v. 29, n. 3, p.04016233-04016233, mar. 2017. American Society of Civil Engineers (ASCE). Disponível em: <http://dx.doi. org/10.1061/(asce)mt.1943-5533.0001757>. Acesso em: 18 jun. 2017. 